\title{
RETRACTED ARTICLE: Synthesis, anti-bacterial, anti-fungal and cytotoxic properties of novel pyrimidine derivatives from chromen-2-one moiety
}

Rangappa S. Keri • Kallappa M. Hosamani •

Ramya V. Shingalapur

Received: 24 November 2009/Accepted: 26 August 2010/Published online: 14 September 2010

(C) Springer Science+Business Media, LLC 2011

This article has been retracted due to self-plagiarism; a significant proportion of the content was previously published in another journal. 